\title{
DEMOCRACIA DIRECTA EN EL PARTIDISTA ESTADO FEDERAL ALEMÁN ${ }^{1}$
}

\author{
FRANK DECKER \\ Director del Seminario de Derecho Público \\ Universidad de Bonn
}
SUMARIO
I. Introducción.
II. Democracia directa en las Constituciones de los Länder alemanes.
III. ¿La legislación producto de la democracia directa tiene el mismo rango que las le- yes sancionadas por el parlamento?
IV. Elementos plebiscitarios y parlamentaris- mo de mayorías.
V. Una versión más acotada de la legisla- ción popular.

\section{INTRODUCCIÓN}

La posibilidad de incorporar elementos plebiscitarios a nivel nacional comenzó a discutirse en Alemania hacia finales de la década de 1980. Hasta ese momento se partía de la base de que la Constitución prohibía la introducción de elementos de la democracia directa más allá del ámbito de aplicación de los arts. 29 y 118, en los que se establecía la reestructuración del territorio federal. Por el contrario, estaba claro que cualquier ampliación del instrumento plebiscitario presuponía una reforma constitucional, dado que el actual art. 76.1 deposita la iniciativa legislativa en forma concluyente en el gobierno nacional, el Parlamento y el Bundesrat. Por otra parte, el apartado 1 del art. 77 establece

1 Este trabajo es traducción española del publicado en el suplemento "Aus Politik und Zeitgeschichte" de Das Parlament, n. ${ }^{\circ}$ 10, marzo de 2.006. 
que las leyes federales son aprobadas por el Bundestag. Más allá de estas restricciones, prevalece el criterio de que la Constitución por sí misma no impide la introducción de los elementos de democracia directa. En ese sentido, durante mucho tiempo las ciencias jurídicas y políticas sostuvieron una interpretación pronunciadamente anti-plebiscitaria de la Constitución, en tanto que actualmente el debate en torno de la democracia directa ya no gira básicamente en torno a argumentos jurídicos sino políticos.

La opinión según la cual la Constitución admitiría la celebración de plebiscitos se sustenta en el texto del art. 20.2, que dispone que uel poder público es ejercido por el pueblo mediante elecciones y votaciones..... Se entiende que la asamblea constituyente no interpretó el principio democrático exclusivamente como de tipo representativo. Así se traduce, por otra parte, en la génesis de este texto en el Consejo Parlamentario ${ }^{2}$. Por lo tanto una ampliación plebiscitaria de la Constitución no estaría reñida con el art. 79.3, que ampara los elementos básicos del orden público establecidos en el apartado 1 del art. 20 de cualquier modificación por parte del constituyente. Semejante violación sólo debería suponerse si la democracia directa afectara a otros principios consagrados por el art. 2 -por ejemplo, «la participación de los länder en el proceso legislativo" — ${ }^{3}$. De hecho, la participación del Bundesrat en un proceso legislativo plebiscitario plantea considerables problemas constitucionales, sobre los que volveremos más adelante.

La tesis de que la democracia directa no es inconstitucional se ve avalada, además, por lo establecido en el art. 28.1, que somete el orden constitucional en los länder a los principios del estado de derecho republicano, democrático y social "en el sentido de esta Constitución". Si nadie pone seriamente en tela de juicio la compatibilidad de los elementos plebiscitarios en las constituciones de los estados con las disposiciones establecidas en el apartado 1 del art. 28, ¿por qué habrían de contradecir entonces el principio democrático a nivel federal? Claro que esto no significa que exista, a la inversa, la obligación positiva de incorporar elementos plebiscitarios en la Constitución ${ }^{4}$. La homogeneidad del orden constitucional no es igual a su identidad. A nivel de los länder, una reforma constitucional también tendría la posibilidad de volver a eliminar los elementos de la democracia directa y retornar a un sistema puramente representativo.

2 Cfr. CLAUS-HENNING: Obst, Chancen direkter Demokratie in der Bundesrepublik Deutschland. Zulässigkeit und politische Konsequenzen, Colonia 1986, pág. 86 y ss.

3 HANS-PETER HUFSCHLAG. Einfübrung plebiszitärer Komponenten in das Grundgesetz? Verfassungsrachtliche Möglichkiten und verfassungspolitische Konsquenzen direkter Demokratie im vreinten Deutschland, Baden-Baden 1999, pág. 113 y ss.

4 Cfr. KARSTEN BUGIEL, Volkswille und representative Entscheidung. Zulässigkeit und Zweckmäbgkeit von Volksabstimmungen nach dem Grundgesetz. Baden-Baden, 1991, pág. 309 y s. 


\section{DEMOCRACIA DIRECTA EN LAS CONSTITUCIONES DE LOS LÄNDER ALEMANES}

Considerando que el art. 28 Const. concede a los länder considerable libertad en la organización de sus sistemas de gobierno, sorprende la homogeneidad que presentan las diferentes constituciones de los estados ${ }^{5}$. En lo relativo a la democracia directa, ello se traduce en que los länder introdujeron los plebiscitos a nivel de los estados y en el comunal. Por otra parte - y lo que es más importante aún-, optaron por un modelo único para el que se impuso el concepto de "legislación popular" (Volksgesetzgebung) y cuyo elemento central es la denominada iniciativa. Le concede al pueblo la posibilidad de poner en la agenda legislativa un determinado tema, sobre el que eventualmente deberá tomarse alguna decisión. Según la opinión unánime de la doctrina, la iniciativa (positiva) constituye el instrumento más fuerte de democracia directa, ya que en este caso, las ciudadanas y ciudadanos toman el lugar del legislador parlamentario. La iniciativa positiva se diferencia así de la mera "iniciativa de veto" (conocida en Suiza como "referéndum facultativo"), mediante la que a instancias de una iniciativa popular una ley ya aprobada puede volver a someterse a votación, como así también a un referéndum simple a iniciativa de uno de los órganos públicos (en general, a iniciativa del gobierno) ${ }^{6}$. Es significativo que todas las constituciones estatales prevean el instrumento de la "legislación popular" en dos o tres niveles, en tanto que las dos variantes mencionadas en último término no están previstas en ninguna de ellas ${ }^{7}$.

La preferencia por la iniciativa positiva está profundamente enraizada en la historia constitucional alemana y sus orígenes se remontan a mediados del siglo $\mathrm{XIX}^{8}$. En el contexto internacional, en cambio, aparece como una experiencia más bien singular. Dejando a un lado estados pequeños como Liechtenstein o San Marino, en Europa solo existen seis países - Italia, Lituania, Suiza, Eslovaquia, Eslovenia y Hungría- que conceden a sus ciudadanos el derecho de anular una legislación aprobada por el Parlamento mediante una iniciativa de veto. Cuatro de estos países —-Lituania, Suiza, Eslovaquia y Hungría- conce-

5 La homogeneidad no se hace extensiva sólo a la forma que adquiere la democracia directa, sino también al derecho electoral y a la forma de gobierno parlamentario. Cfr. FRANK DECKER, "Die Regierungssysteme in den Ländern", en el del mismo autor (ed.), Foderalismus an der Wegscheide?, Wiesbaden 2004, págs. 169-201.

6 Otra variante es el referéndum obligatorio, en el que el plebiscito está previsto de antemano en la Constitución. Respecto de la tipología de la democracia directa y sus diferentes procedimientos cfr. FRANK DECKER, "Die Systemverträglichkeit der direkter Demokratie. Dargestelt an der Disskusión um die Einführung vol plebiszitären Elementen in das Grundgesetz", en Zeitschrift für Politikwissenschaft, 15 (2005) 4, pág. 1113 y ss.

7 Cfr. BÄRBEL MARTINA WEIXNER, Direkte Demokratie in den Bundesländern, Verfassungsrechtlicher und empirischer Befund aus politikwissenschaftlicher Sicht, Opladen 2002, pág. 143 y ss.

8 Cfr. REINHARD SCHIFFERS, Elemente direkter Demokratie im Weimarer Regierungssystem. Düsseldorf, 1971, pág. 17 y ss. 
den al pueblo, además, un derecho legislativo positivo que, no obstante, no se extiende a todas las materias. Particularmente amplio es el ámbito de aplicación en Eslovaquia y Lituania: en estos países existe la posibilidad de presentar una iniciativa para someter a plebiscito una reforma constitucional o también leyes simples (o partes de las mismas). En Suiza, por el contrario, la legislación positiva se limita hasta la fecha a la iniciativa constitucional ${ }^{9}$.

Por un lado, cabe destacar que existen posibilidades de comparación muy acotadas en Europa, porque además de Alemania, solo existen otros tres países que pueden calificarse de federalistas en el sentido estricto (constitucional), a saber: Bélgica, Austria y Suiza. Por el otro, es menester señalar que el debate alrededor de la introducción de elementos plebiscitarios gira en forma casi exclusiva en torno a la iniciativa popular. En consecuencia, la mayoría de las propuestas prevé incorporar a nivel federal el modelo de legislación popular tal cual existe en los länder y las comunas. De convertirse estos proyectos en ley, Alemania superaría incluso a la propia Suiza en el alcance de la legislación popular.

Claro que ello presupone que no se tome en consideración la efectiva aplicabilidad del instrumento. En este punto se evidencia lo diametralmente opuesto. Con su voto a favor de la iniciativa popular, las constituciones de los estados federados reflejan un espíritu pro-plebiscitario que, traducido a la práctica, demuestra no serlo tanto. Un problema menor es en este contexto el hecho de que en el federalismo alemán los ländertienen escasas competencias legislativas. Un tema más complejo son las barreras que los constituyentes establecieron para los derechos populares, que van desde la exclusión de numerosos temas hasta la exigencia de un quórum casi imposible de alcanzar ${ }^{10}$. Estas trabas han determinado que la democracia directa no haya alcanzado nunca protagonismo y que haya jugado hasta el día de hoy un papel menor en la vida constitucional de los länder. Visto desde esa perspectiva, la decisión a favor del instrumento potencialmente más abarcador de la iniciativa y su "castración" fáctica a través del derecho (y la jurisprudencia) constitucional constituyen en Alemania dos caras de una misma moneda. En ese sentido, hay que coincidir con quienes les asignan a los procedimientos plebiscitarios una función meramente simbólica ${ }^{11}$.

Teniendo en cuenta que el modelo de democracia directa prevista en las constituciones de los länder es objeto de por sí de una transferencia directa al nivel federal, podría plantear problemas por otras dos razones más: en primer lugar, la distribución de las competencias en el sistema federal determina que

9 Cfr. SILVANO MÖKLI: "Direktdemokratische Einrichtungen und Verfahren in den Mitgliedstaaten des Europarates", en Zeitschrift für Parlamentsfragen, 29 (1998) 1, pág. 100 y ss.

10 Para una recopilación de las regulaciones correspondientes, ver ANDREAS KOST (ed.), $D i$ rekte Demokratieinden deutschen Ländern. Eine Einführung. Wiesbaden 2005, pág. 367 y ss.

11 Así lo puntualiza, entre otros, OTMAR JUNG, "Direkt Demokratie als Herausforderung der Repräsentativen Demokratie. Eine Auseinandersetzung mit Werner J. Patzelt", en German Studies Review, 25, (2002) 2, pág. 292. 
en ambos niveles se legislen materias totalmente diferentes. Si es cierto que los procedimientos plebiscitarios se muestran como apropiados sobre todo en un espacio reducido, resulta poco conveniente introducir a nivel federal un instrumento de alcance aún mayor al que existe a nivel de los ländery las comunas, como el que previó el proyecto de ley presentado por el oficialismo durante el anterior gobierno integrado por socialdemócratas y verdes en $2002^{12}$. Además, a nivel nacional se ve dificultada por las diferentes condiciones institucionales dentro de las cuales se desenvuelve la política de los länder y la política nacional. Aquéllos, por ejemplo, no poseen una segunda cámara a la que debe darse intervención en el proceso legislativo. También puede haber diferencia en las estructuras de los sistemas de partidos, lo que hace que un elemento de corrección plebiscitario aparezca como particularmente conveniente. Un ejemplo que salta a la vista es Baviera, donde el amplio dominio de la CSU dificulta un funcionamiento normal del sistema parlamentario (que vive de la alternancia entre gobierno y oposición).

\section{III. ¿TIENE EL MISMO RANGO LA LEGISLACIÓN PRODUCTO DE LA DEMOCRACIA DIRECTA QUE LAS LEYES SANCIONADAS POR EL PARLAMENTO?}

Al igual que los procedimientos parlamentarios, los plebiscitarios se miden en función de dos criterios normativos. Por un lado, su finalidad es contribuir a democratizar la toma de decisiones y otorgar una mayor legitimación, y por el otro, incrementar la eficiencia de las decisiones (o al menos no afectar esa eficiencia negativamente) ${ }^{13}$. Es evidente que los plebiscitos no despliegan estos efectos de forma aislada, sino solo en el contexto general del sistema de gobierno, con cuyos restantes elementos armonizan más o menos bien. Eso significa al mismo tiempo que el debate de fondo debe centrarse en el cómo y no tanto en el si se habrán de introducir elementos plebiscitarios o no. En otras palabras, la elección y la forma de los procedimientos directos adquiere para el funcionamiento del sistema político una importancia mayor que la diferencia básica entre representación plebiscitaria y parlamentaria ${ }^{14}$.

12 Para mayores detalles respecto de la crítica que despierta el proyecto, cfr. F. DECKER (n.a.p.5), págs. 1126-1127.

13 Sobre la eficacia de las decisiones adoptadas mediante el instrumento de la democracia directa existe todo un cúmulo de estudios empíricos que en su mayoría llegan a una apreciación positiva. Cfr. p. ej., GEBHARD KIRCHGÄSSNER, "Direkte Volksrechte und die Effizienz des demokratischen Staates", en ORDO. Jahrbuch für fie Ordnung von Wirtschaft und Gesellschaft, 52 (2001), págs. 155-173.

14 Cfr. JÜRGEN FIJALKOWSKI, "Erfahrungen mit Volksabstimmungen zu Sachfragen. Erfordernisse und Ergebnisse kategorialer Differenzierung", en HANS-DIETER KLINGEMANN-WOLFGANG LUTHARDT (ed.), Wohlfahrtsstaat, Sozialstruktur und Verfassungsanalyse, Opladen, 1993, pág. 151. 
En el caso de Alemania, la pregunta que primero salta a la vista con respecto a la compatibilidad entre su sistema político y los procedimientos plebiscitarios está referida a la primacía de la Constitución. Tal principio postula que una ley aprobada por el pueblo esté sujeta al control constitucional igual que una ley parlamentaria. Pero si se trata de dediciones básicas para la orientación del Estado, a las que adscribe una mayor legitimidad cuando son el resultado de la democracia directa, la Corte Constitucional no podría invalidar un plebiscito de este tipo sin socavar su propia legitimación ${ }^{15}$. La mayoría de quienes defienden la introducción del plebiscito intentan soslayar este problema mediante un control constitucional ex ante. Es decir que en caso de que existan dudas fundadas sobre la constitucionalidad de una ley reclamada por el pueblo, se recurra al tribunal constitucional en Karlsruhe antes de convocar el plebiscito. Podrían plantear el caso, igual que en el caso del control de norma abstracto, el gobierno nacional, el gobierno de un land o un tercio de los diputados nacionales ${ }^{16}$.

Problemas singularmente más graves plantea una posterior anulación o modificación de la ley popular por parte del Parlamento. Esta problemática tomó estado público por primera vez en 1999, cuando la legislatura del land Schleswig-Holstein revocó, al cabo de apenas un año, un plebiscito que rechazó la forma ortográfica ${ }^{17}$. Dado que las leyes parlamentarias y populares tienen igual rango desde el punto de vista normativo-constitucional, esta posibilidad debe existir básicamente. No obstante, sería un error suponer una total simetría entre ambos tipos de procedimientos. Como el pueblo decide en forma directa solo sobre unas pocas leyes consideradas especialmente importantes, resulta conveniente concederles mayor estabilidad que a las leyes parlamentarias $^{18}$. Una posible solución sería establecer cierto plazo dentro del cual el legislador parlamentario no puede revocar o modificar la ley aprobada mediante la voluntad popular.

15 Cfr. UWE KRANENPOHL, “Verkürzen Verfassungsrichter Volksrechte? Verfassungspolitische Probleme der Volksgesetzgebung", en Gesellschaft-Wirtschaft-Politik, 52 (2003) 1, págs. 37-46.

$16 \mathrm{El}$ proyecto de ley presentado por la socialdemocracia y los verdes prevé la normativa correspondiente.

17 Otro tanto ocurre actualmente en Hamburgo, donde el gobierno de la CDU proyecta introducir sustanciales modificaciones al nuevo derecho electoral aprobado por una iniciativa popular en 2004 que promete un fortalecimiento de las posibilidades de elección democrática del electoral. Ya con anterioridad, la legislatura había ignorado una resolución popular mediante la cual una clara mayoría del electorado se había pronunciado a favor de que los grandes hospitales continuaran siendo públicos. No obstante, la acción interpuesta por la iniciativa popular ante la Corte Constitucional del land confirmó el criterio sostenido por el gobierno y la legislatura en el sentido de que la iniciativa votada solo contenía una exhortación al gobierno y no tenía efectos vinculantes.

18 Normas comparables existen en otros países también. Las constituciones de los estados norteamericano que contemplan elementos plebiscitarios, por ejemplo, prevén que las leyes populares no queden sujetas al veto del gobernador. 


\section{ELEMENTOS PLEBISCITARIOS Y PARLAMENTARISMO DE MAYORÍAS}

Este último problema queda relativizado por la inserción del procedimiento parlamentario en la competencia entre los partidos. Si la mayoría parlamentaria desea revocar una ley aprobada por la voluntad popular, será aconsejable asegurarse el apoyo de la oposición, ya que, de lo contrario, ésta podría aprovechar la oportunidad para hacer un frente común con los ciudadanos. La introducción y ampliación del instrumento durante la década de los 80 , generalmente ha pedido de la oposición, demostró claramente que en razón de su popularidad, la democracia directa es un tema particularmente apto para promover la competencia entre los diferentes partidos. Otro tanto puede decirse de la posterior práctica. Si los elementos plebiscitarios constituyen un potencial elemento de corrección de los procedimientos de decisión representativos, los representantes harán todo lo posible por controlar su uso ${ }^{19}$. En tal sentido, no tiene mayor sentido la esperanza manifestada por algunos de que una democracia directa puede hacer retroceder la influencia de los partidos y recortar su posición en el sistema político ${ }^{20}$.

Eso significa, al mismo tiempo, que allí donde los plebiscitos están dotados de derechos de iniciativa, éstos minan el principio de la alternancia en el gobierno en el que se basa idealmente el sistema parlamentario de mayorías ${ }^{21}$. Si la oposición tiene la posibilidad de desactivar con posterioridad una ley aprobada por la mayoría oficialista por la vía del plebiscito, el gobierno naturalmente intentará calcular de antemano cuáles serán las posibles resistencias contra su proyecto y considerarlas en sus planes. Es decir que la lógica de la iniciativa popular es "consensual", se encarga de que se opere una mayor inclusión de los diferentes intereses. En Suiza, esto ha determinado que en el transcurso de los años todos los grandes partidos y las organizaciones intermedias fueran integrados en el proceso de gobierno y se constituyeran en un sistema de concordancia firmemente institucionalizado. En Suiza, la democracia directa, practicada vitalmente y la ausencia casi total de una competencia entre partidos, son dos caras de una misma moneda ${ }^{22}$.

Desde un punto de vista institucional, pueden esgrimirse dos argumentos a favor de un fortalecimiento del momento consensual mediante la introducción de la legislación popular en Alemania. Por un lado, los procedimientos plebiscitarios contrarrestarían las tendencias del bloqueo que se dan en el sistema de gobierno alemán como producto de la combinación de una fuerte

19 Cfr. HEIDRUN ABROMEIT, "Nutren und Risiken direktdemokratischer Instrumente", en CLAUS OFFE (ed.), Demokratisierung der Demokratie, Francfort/M. Nueva York 2003, pág,. 110.

20 Cfr. HANS HERBERT VON ARNIM, Vom schönen Schein der direkten Demokratie. Politik obne Verantwortung -am Volk vorbi, Munich 2000.

21 Cfr. F. DECKER (n.a.p. 5), pág. 1130 y ss.

22 Cfr. WOLF LINDER, Schweizerische Demokratie. Institutionen - Prozesse - Perspektiven, Berna-Stuttgart-Viena 1999, pág. 311 y ss. 
competencia partidaria y una interdependencia política constitucional igualmente fuerte. Por el otro, sería una respuesta a la problemática de las graves debilidades que la competencia entre partidos presenta como mecanismo de solución a los problemas, por ejemplo, al descuidar sistemáticamente los intereses de las futuras generaciones ${ }^{23}$. La introducción de los procedimientos directos trasladaría las tendencias plebiscitarias de la esfera electoral al ámbito de las políticas específicas. Obviamente, ello no despojaría a la competencia entre partidos de su función electoral. La conserva por el solo hecho de que básicamente es necesario poder deshacerse de un gobierno corrupto o inepto. Para el diseño de los contenidos políticos, en cambio, se plantea la pregunta de si no sería mejor acotar el principio de mayoría y focalizar más la democratización en los elementos deliberativos de los procesos de decisión para fortalecerlos en su capacidad de respuesta. Planteados en forma razonable, los plebiscitos podrían ser al mismo tiempo un escudo contra las tendencias populistas presentes en la competencia entre los partidos, que se multiplican como resultado de los cambios en el marco social y político general ${ }^{24}$.

\section{LA INCLUSIÓN DEL BUNDESRAT}

En tanto que la introducción de la iniciativa popular (positiva) podría conducir a un cambio muy válido en la práctica parlamentaria, plantearía considerables problemas constitucionales con vistas a un cogobierno federativo. La doctrina ha ignorado largamente estos problemas y solo en los últimos años se ha desatado un encendido debate en torno a los mismos ${ }^{25}$. El punto de partida normativo es sencillo: conceder al pueblo al posibilidad de actuar él mismo como legislador evidentemente sólo cobra sentido cuando en la aprobación definitiva de la ley puede desplazar a los órganos públicos, es decir, ocupar plenamente el lugar de éstos ${ }^{26}$. No sería compatible con ese carácter la necesidad de contar con el acuerdo del Bundesrat o de cualquier otro órgano representativo. Su participación plantearía problemas prácticamente insolubles. Por ejemplo, no podría haber leyes que admitieran la interposición de un veto por parte del Bundesrat, el pueblo debería votar de inmediato por segunda vez

23 Cfr. METER GRAF KIELMANSEGG, “Coñeen Demokratien zukunftsverant-wortlich handeln?", en Merkur, 57 (2003) 7, págs. 583-594.

24 Respecto de las causas y efectos colaterales de este cambio, cfr. FRANK DECKER, "Politikverdrossenheit ohne Ende? Zur Krise der deutschen Parteiendemokratie", en Gesellschaft - Wirtschaft - Politik, 54 (2005) 1, págs. 101-125; UWE JUN, "Populismos als Regierungsstil in westeuropäischen Parteiendemokratien: Deutschland, Frankreich und Grobbritannien" ", en FRANK DECKER (ed.), Populismus, Wiesbaden 2006, págs. 233-254.

25 Cfr. z.B. OTMAR JUNG, "Direkte Demokratie und Föderalismus. Die grundsätzliche Mitwirkung der Länder bei der Volksgesetzgebung im Bund", en Stefan Brink - Heinrich Amadeus Wolft (Hrsg.), Gemeinfwohl und Verantwortung, Festschrift für Hans Herbert von Arnim zum 65, Geburtstag, Berlín 2004, págs. 353-366.

26 Cfr. HARTMUT MAURER, Plebiszitäre Elemente in der repräsentativen Demokratie, Heilderber 1997, pág. 27. 
la misma ley. Otro tanto puede decirse respecto de la convocatoria de la instancia mediadora y la consiguiente mediación, en la que sólo pueden intervenir representantes electos o delegados y que, por ende, también dejarán de tener vigencia $^{27}$. Sin embargo, estas instituciones constituyen elementos funcionales irrenunciables del cogobierno federativo.

Pocos autores consideran hoy forzoso un derecho de acuerdo del Bundesrat para la posterior resolución legislativa. La mayoría de los constitucionalistas sostiene que la inalterabilidad del art. 79.3, sólo protege "la participación básica de los länder en la legislación", sin disponer nada acerca de la forma en la que esta participación debe materializarse. Dicho en términos positivos, esto significa que la participación también puede darse a través de la "ciudadanía de

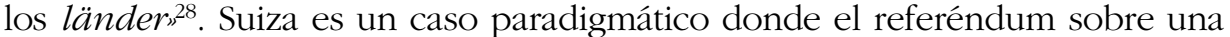
ley no solo debe contar con la mayoría del pueblo ("mayoría popular"), sino también con la mayoría de los ciudadanos por cantones ("mayoría cantonal"). El ciudadano solo emite un voto que cuenta al mismo tiempo como voto popular y voto cantonal.

La transferencia de este modelo a Alemania tendría la ventaja de que podría considerar la ponderación de votos de los länder en el Bundesrat; en tal caso, la mayoría de los habitantes de un land serían idéntica con los votos de ese land en el Bundesrat. En su momento, los partidarios de la democracia directa consideramos que la solución era lo suficientemente consistente como para incorporarla en su proyecto de 1993 sobre introducción de elementos plebiscitarios, que más tarde fuera presentado a la Comisión Constitucional Conjunta. Cuando en 2002 la coalición oficialista formada por la socialdemocracia y los verdes presentó su propio proyecto, pudo basarse en este concepto.

Las desventajas que plantea una solución que considera también una mayoría por land se evidencia en un análisis más profundo. Surgen del carácter confederativo del federalismo alemán que determina que los estados integrantes dependan funcionalmente de un órgano que proteja sus intereses. Es el caso, por ejemplo, en que una ley afecta a las finanzas de un land o en que el Estado nacional interviene mediante disposiciones administrativas generales y la creación de organismos públicos en las competencias de los länder en la ejecución de las leyes nacionales. Este último aspecto explica también la estructura universalmente única del Bundesrat como órgano de representación del Ejecutivo y marca al mismo tiempo la diferencia decisiva con respecto a Suiza. Allí no es necesario que la cámara representante de los cantones e incorpore el conocimiento administrativo del nivel regional en el proceso legislativo de la Confederación porque los cantones son efectivamente autónomos en el plano administrativo 29 .

27 Cfr. CHRISTOPH DEGENHART, «Direkte Demokratie auf Bundesebene nach dem Grundgesetz. Anmerkungen zu einem Gesetzentwurf", en KLAUS STERN u.a. (ed.), Gedächtnisschrift für Joachim Burmeister, Heildeberg 2005, pág. 98

28 Cfr. TIM WEBER, «Sind Volksgesetzgebung und Föderalismus vereinbar?", en Zeitschrift für direkte Demokratie, 15 (2003) 3, págs. 30-32

29 Cfr. W. LINDER (n.a.p. 21), pág. 159 y ss. 
Contra este argumento podría aducirse que la mayoría de las leyes solo abarca asuntos rutinarios que permitirían ejercer la competencia administrativa por otra vía, por ejemplo, a través de informes de expertos en la etapa anterior al plebiscito (siguiendo el ejemplo del primer tratamiento de los proyectos de ley en el recinto $)^{30}$. Por otra parte, entre las leyes importantes habrá también muchos casos en los que los intereses de los länder sirven solo de pantalla y el rechazo por parte del Bundesrat se debe exclusivamente a razones de conveniencia partidaria. No obstante, por más razonable que parezca en estas condiciones soslayar la participación de la segunda cámara, su exclusión no es una solución viable. En efecto, en tal caso, el gobierno tendría la posibilidad de impulsar sus proyectos de ley por la vía plebiscitaria cada vez que se enfrente a una mayoría opositora en el Bundesrat. La respuesta a la desnaturalización de lo constitucional sería, entonces, la desnaturalización de otro instrumento. Si consideramos estas particularidades del sistema, poco queda de la aparente elegancia del modelo suizo.

\section{UNA VERSIÓN MAS ACOTADA DE LA LEGISLACIÓN POPULAR}

Del análisis anterior se deriva que no es recomendable adoptar en el plano de la Constitución nacional el modelo de una legislación popular en dos o tres niveles, tal como existe hoy en todos los länder alemanes. Además de que el elemento central de este modelo, la iniciativa legislativa (positiva), casi no tiene exponentes en el contexto internacional, tampoco se manifiestan efectos considerables en el nivel de los Estados miembros, dado que las condiciones extremadamente restrictivas de su aplicación determinan que tengan muy poca importancia en la práctica.

Un modelo viable de democracia directa a nivel nacional debería renunciar a la introducción de la iniciativa legislativa (positiva). Esto permitiría desactivar en gran medida la problemática del quórum, la exclusión de determinadas temáticas y otros requisitos jurídicos que, de lo contrario, conducirían a disputar permanentes ante el Tribunal Constitucional Federal. Por otro lado, no habría que incluir en la discusión la problemática del Bundesrat, que en el caso de la democracia directa a nivel de los länder no se plantea. Un concepto de democracia directa aplicable, compatible con el sistema y útil en sus efectos institucionales podría quedar limitado a dos elementos: una iniciativa de veto siguiendo el modelo suizo y un referéndum simple convocado por iniciativa del gobierno ${ }^{31}$.

30 Cfr. GÜNTHER BECKSTEIN, “Volksgesetzgebung auf Bundesebene und Bundesstaatliche Ordnung", en HANSS-DETLEF HORN (ed.), Recht im Pluralismus, Festschrift für Walter Schmitt Glaeser zum 70. Geburtstag, Berlín 2003, pág. 124 y ss.

31 Otras variantes conformes con el sistema serían una iniciativa de ley meramente consultiva (petición popular calificada) así como un referéndum constitucional obligatorio. Razones de espacio impiden ahondar en estas variantes. Cfr. F. DECKER (n.a.p. 5), pág. 1140 y ss. 
La iniciativa de veto le daría al pueblo la posibilidad de someter leyes ya sancionadas a un nuevo voto y, eventualmente, revocarlas ${ }^{32}$. Aplicado por los partidos de oposición, equivaldría a un recurso ante el Tribunal Constitucional o el bloqueo de un proyecto de ley en el Bundesrat. Sin embargo, el veto plebiscitario sería más funcional como "estrategia deslegitimadora" porque no obligaría a la oposición a esgrimir supuestos argumentos de orden constitucional cuando en verdad se trata de diferencias partidarias ${ }^{33}$. En ese sentido, la iniciativa de veto se insertaría bien el actual sistema de fuerte interdependencia política constitucional.

Sin embargo, el veto popular solo puede desplegar un efecto consensual si la mayoría gobernante tiene la posibilidad de recurrir a la vez a medios plebiscitarios para quebrar eventuales bloqueos en el proceso de toma de decisión. Es decir, que el gobierno debería contar con la posibilidad de ratificar sus resoluciones por medio del voto popular aun en contra del voto negativo del Bundesrat $^{34}$. Si obtuviera el respaldo por esta vía, quedaría desarticulada la crítica de la oposición. A la inversa, un referéndum perdido podría servir como resorte institucional para convocar a elecciones anticipadas. Esto se aproximaría al derecho de disolución plebiscitario tal cual existe hoy en siete constituciones de otros tantos länder y sería una posibilidad de soslayar el procedimiento, constitucionalmente cuestionable, previsto en el art. 68 de la Constitución.

Es sintomático que las variantes propuestas han tenido poco espacio en el debate acerca de un "diseño" óptimo de la democracia directa. Para los partidarios del plebiscito, que no se cansan de recomendar la iniciativa legislativa, parecerían ser propuestas de una variante de participación plebiscitaria de menor valía, que no merece la pena ser implementada. Sin embargo, los efectos sistémicos que surgirían de una introducción simultánea de la iniciativa de veto y del referéndum serían considerables. Decir que la democracia directa no despliega este efecto tanto por su uso real cuanto por la sola posibilidad de recurrir a ella es una perogrullada. Al estar disponible como opción, obliga a los actores políticos a tomar en consideración los intereses de los grupos que pueden ser convocados para un referéndum y buscar el consenso. Esto no significa que Alemania vaya a convertirse en una democracia de concordancia al estilo suizo. Sin duda se interponen tanto la estructura básica del sistema político como también nuestra tradición constitucional. No obstante, la introducción de los plebiscitos incorporaría un estilo político más orientado al consenso que en el más largo plazo podría cambiar la cultura parlamentaria, lo que per-

32 Como punto de referencia podría servir la cláusula del 5\% de la población con derecho a voto, prevista en el proyecto de ley presentado en 2002 por la socialdemocracia y los verdes para la introducción de una iniciativa popular.

33 Cfr. HANS METER BULL, "Keine Angst vor dem Volksentscheid", en Die Zeit del 31.3.1989, pág. 4.

34 Para evitar una anulación total de la segunda cámara, se podría conceder un segundo derecho a veto contra un voto popular positivo que, no obstante, exigiría un quórum más alto (mayoría de dos tercios). 
mitiría un nuevo acercamiento de los ciudadanos a las instituciones que los representan.

La mayor ventaja de esta versión más acotada de legislación popular reside en que desactivaría gran parte de los argumentos de quienes hoy critican la introducción del plebiscito. En tal caso no podría argumentarse que el instrumento de la democracia directa no es apto para las complejas materias de la política nacional ni tampoco que pondría en duda el federalismo. También se podrían disipar más fácilmente las dudas básicas sobre la capacidad de juicio del pueblo, dado que en ambos casos se mantendría el "pre" de la representación parlamentaria. Tanto los partidarios de la democracia directa como sus detractores concentran sus argumentos exclusivamente en la iniciativa legislativa (positiva). Es aquí donde radica el verdadero problema del debate iniciado en Alemania y que hasta ahora ha impedido un abordaje realista de lo que la democracia directa puede aportar y de lo que no puede aportar. Sólo cuando esto se modifique y las propuestas institucionales estén debidamente encarriladas, se podrá pensar en hacer un nuevo intento por complementar la Constitución con elementos plebiscitarios.

ABSTRACT. Until the end of the 80's it was believed that the Federal Constitution forbade the introduction of elements of the direct democracy beyond the range of matters of articles 29 and 118. Any other application of the formula of plebiscite was considered unconstitutional. In Germany the compatibility between its political system and the procedures of direct democracy refers to the primacy of the Constitution. 